\title{
Laser gingivectomy in orthodontic treated patient
}

\author{
Iva Yordanova, Svetlana Dineva
}

Faculty of Dental Medicine. Varna, Bulgaria;

\begin{abstract}
Background: Gingival enlargement is a common feature of gingival diseases. The treatment of gingival enlargement is based on the understanding of the etiology and pathology of this condition and can be treated by gingivectomy approach. The use of diode lasers in gingivectomy procedure reduces the level of postoperative hazards and facilitate the healing process after this manipulation. The literature survey reports that this technique shows good results, less postoperative inflammation and less postoperative pain and improved healing result in the surgical sites.
\end{abstract}

Purpose: The aim of this case report is to present the satisfied aesthetic outcome of laser gingivectomy approach and less postoperative pain and inflammation in postsurgical healing period.

Material and methods: A laser gingivectomy is performed in young orthodontic treated patient for removing gingival enlargements in the zone of interdental gingival tissues in both jaws - on vestibular sites of maxilla and mandibula.

Results: The laser gingivectomy, using diode laser, resulted in fast wound healing, with experience of some postsurgical discomfort and no postoperative bleeding.

Conclusion: The performed laser gingivectomy presents satisfactory aesthetic outcome, fast healing process and reduced postoperative discomfort.

Keywords: gingival enlargement; gingivectomy; diode laser 


\section{Background}

Gingival enlargement is a common feature of gingival diseases and can be classified according to etiologic factors and pathologic changes into 5 groups: inflammatory enlargement, drug-induced enlargement, enlargement associated with systemic diseases or conditions, neoplastic enlargement and false enlargements. Depend on position enlargements are divided to diffuse, marginal and papillary. According to the distribution to: generalized and localized.(1)

The etiologic factors that can induce gingival enlargement can vary from plaque-induced inflammation due to some local factors to idiopathic and neoplastic enlargements. The clinical characteristic of gingival enlargements are fibrous interdental gingival tissues or diffuse and swelling overgrown inflammated gingiva. The gingival enlargements leads to plaque retention, aesthetic dissatisfaction and impaired function during mastication.(2)

Gingival enlargement therapy depends on the understanding of its etiology and pathology and it is estimated individually to each patient. There is a choice of surgical or nonsurgical approach in treatment of gingival enlargements or combination of both types of therapy. (2)

When the gingival enlargement is characterized by soft and inflamed tissues, it is regularly treated with scaling and root planing. In cases of gingival enlargements characterized by fibrotic tissues with severe excess over the tooth crown and do not respond to and undergo shrinkage after scaling, a surgical therapy is a choice of treatment approach - gingivectomy or an access flap surgery.(3)

The preoperative assessment of the aesthetic risk before surgical manipulations in the aesthetic zone of dentition like gingivectomy procedure depends on some criteria like periodontal phenotype, height of interdental papilla, tooth form, smile line and presence of gingival recessions. The aesthetic risk is higher in cases of thin periodontal phenotype(4), reduced height of interdental papillae(5), triangular tooth form(6), high smile line(7), presence of gingival recessions(8).

The choice of surgical approach depends on the adequate width and thickness of keratinized gingival tissues $(4,9)$, extent of the enlargement and gingival tissues conditions. Localized areas of gingival enlargements can be treated by traditional gingivectomy approach and the generalized areas - by by laser gingivectomy approach. Gingivectomy is a surgical procedure for removing of the overgrown gingival tissues to more apical level tailored to the biological width and create new gingival margin. (10) The biological width is a totality of epithelial attachment and connective tissue attachment and is important not to be affected during gingivectomy.(11) The biological width is significant for maintenance of gingival health and its affection during therapy may result in gingival recession or gingival rebound. An important consideration is the amount of keratinized tissue present.(12)

Due to the exposed connective gingival tissues the gingivectomy can lead to increased postoperative bleeding, postoperative pain, loss of keratinized tissue. This procedure does not permit osseous recontouring (osteoplasty and osteoectomy).

Different approaches can be performed for gingivectomy or gingivoplasty - surgical blades, electrosurgery, chemosurgery, cryosurgery or laser devices. The advantages of using scalpel blade are precise incision and no lateral tissue damage and the disadvantages are bleeding and less visibility, postoperative 
pain. $(9,13)$ In comparison to the conventional gingivectomy, there are some evidence that indicate that reccurence of gingival enlargement is reduced in using of lasers.(14) It has been suggested that the use of lasers reduces the level of postoperative hazards and facilitate the healing process.(15)

The abbreviation for LASER means light amplification by stimulated emission of radiation.(15) Four different types of lasers based on their operating wavelength are known and used in dental therapy: Carbon dioxide laser (CO2), the Diode laser, the Neodymium: Aluminum-Yttrium-Garnet ( $\mathrm{Nd:} Y A G)$ and the Erbium: Aluminum-Yttrium-Garnet (Er: YAG).(17)

Diode laser is becoming one of the most popular types due to its portability, light weight and versatility. The working wavelength of diode lasers for oral soft tissue is $980 \mathrm{~nm}$. The wavelength of diode lasers is easily absorbed by the chromophores (melanin and hemoglobin) in the gingival tissues, while posing little risk of damaging the hard tissue structure. It causes coagulation and drying of the area that will impedes bleeding.(18) The mucogingival complex showed no functional or aesthetic damage and no bone resorption occurred in the involved area. (19) The diode is an excellent soft tissue laser indicated for sulcular debridement and soft tissue surgical procedures.(3)

The better control of laser, less postoperative inflammation and pain and the improved wound healing in the surgical site are all the benefits of using laser in surgery. $(17,20)$

The aim of this case report is to present the satisfied aesthetic outcome of laser gingivectomy approach and less postoperative pain and inflammation in postsurgical healing period.

\section{Case description}

\section{Material:}

An orthodontic treated patient is a 15 years old female, non-smoker, with no systemic diseases, and no medicaments intake. The patient came with aesthetic dissatisfaction in the aesthetic zone of dentition due to excessive gingival tissues at the interdental spaces due to plaque-induced gingival inflammation during period of puberty. She also complained of provoked bleeding from the gums during tooth brushing. (fig.1)

The attending orthodontist recommended a consultation with periodontist for removing the gingival enlargements in the zone of interdental papillae on the vestibular aspect of both dental arches.

A medical history and periodontal status (probing depth, clinical attachment level, height of keratinized gingiva) were recorded. All the measurements were recorded using UNC 15 periodontal probe (University of North Carolina 15). No mobility of frontal teeth are reported. All teeth in the dentition are vital without conservative or prosthetic restorations. 


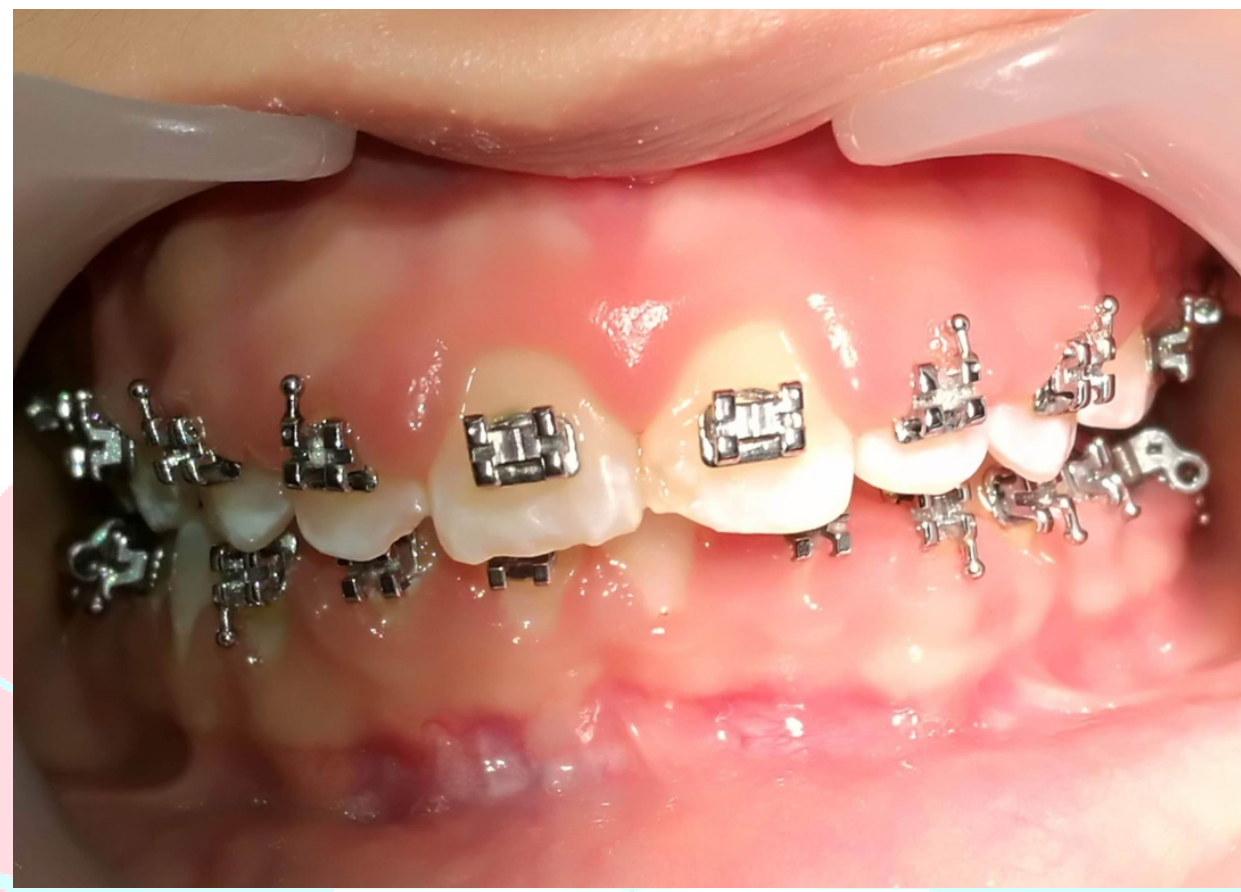

fig.1 Initial state

The radiographic assessment reveals no alveolar bone loss.(fig.2)

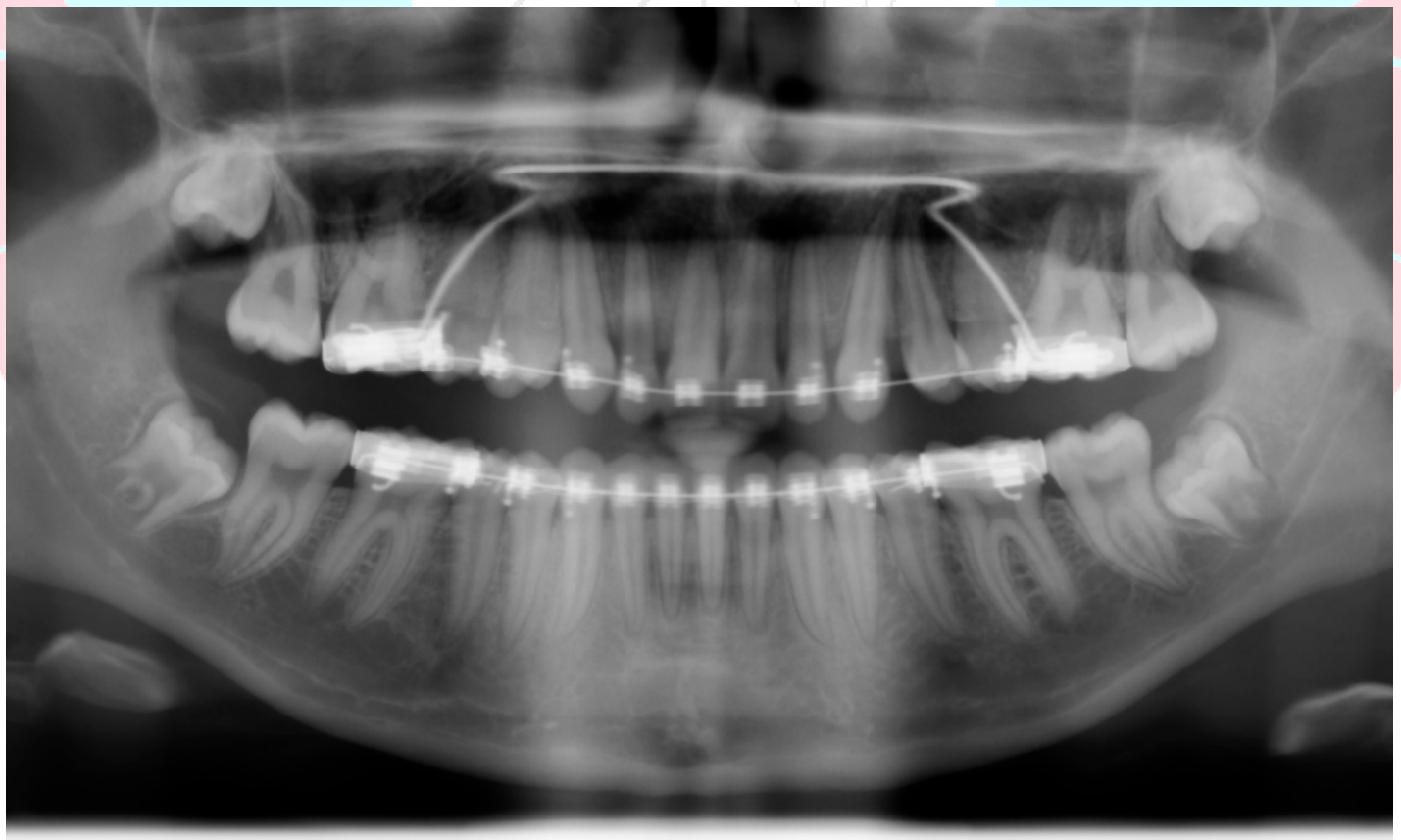

fig.2 Panoramic radiographic assessment 
After periodontal screening of the patient, there are given instructions for controlling the microbial biofilm and proper oral hygiene. Ultrasonic scaling and polishing with a rubber cup and low abrasive polishing paste to the hard dental tissues are performed. A modified Bass brushing method for cleaning the teeth surfaces, interdental cleaning devices and chemical plaque control are carried out to the patient.

There are no contraindications for surgical gingivectomy treatment. The surgical therapy is scheduled after the patient showed an adequate score of plaque index of O'Leary $(<20 \%)$.

Informed consent is signed by the patient's parents before surgical treatment.

\section{Method:}

A laser gingivectomy with gingivoplasty using diode laser is performed. The wavelength of the emitted light energy is $980 \mathrm{~nm}$.

After adequate anesthesia a gingivectomy is done - first on vestibular maxillary gingival tissues and after that on the vestibular mandibular gingiva. The excess of gingival enlargement is removed in the area from the first right molar to the first left molar for both arches. A new gingival margin is created with well-defined edges. (fig.3)

The biological width which is important for the health of gingival tissues, is not affected. The surgical zone is irrigated with saline solution. A chlorhexidine gel $0,2 \%$ is applied over the exposed connective gingival tissue.

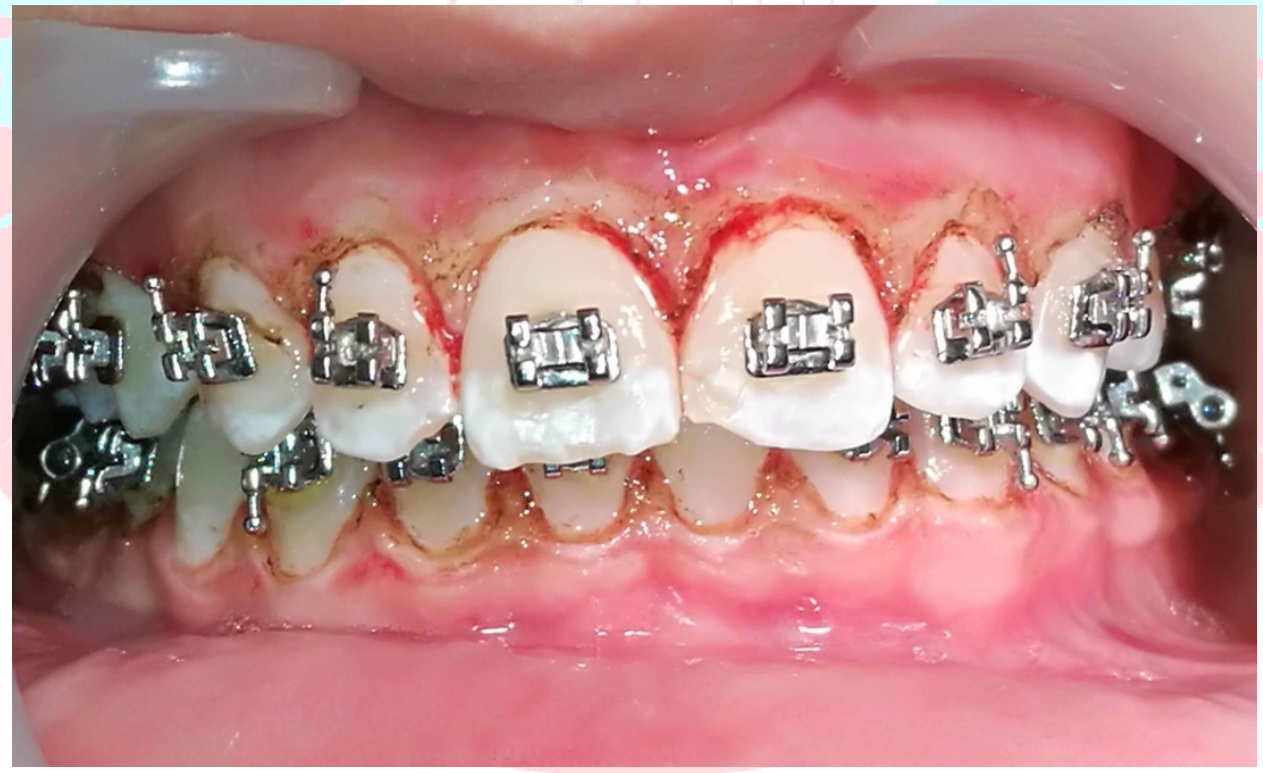

fig.3 Postsurgical view 
Postoperative instructions are given. $0,12 \%$ chlorhexidine rinse solution (Paroex GUM® $0,12 \% \mathrm{CHX}$ ) is prescribed three times daily for $60 \mathrm{sec}$. and the patient is informed to brush with postoperative tooth brush (Elgydium clinic ${ }^{\circledR} 7 / 100$ ). It is not recommended interdental brushing in postsurgical healing period. Elgydium Cicalium spray ${ }^{\circledR}$ (containing PVP, taurine, zinc gluconate) is prescribed for application over the exposed connective gingival tissues for one week.

The patient was recalled 7 days and 14 days after the manipulation for control visits. (fig.4,5) An adequate healing of the surgical wound is noted. The mouth rinse solution is changed with $0,06 \% \mathrm{CHX}$ mouth wash (Paroex ${ }^{\circledR} 0,06 \%$ ) for still 2 weeks. The cleaning of interproximal spaces using interdental brushes (size 0,6 $\mathrm{mm})$ is restored.
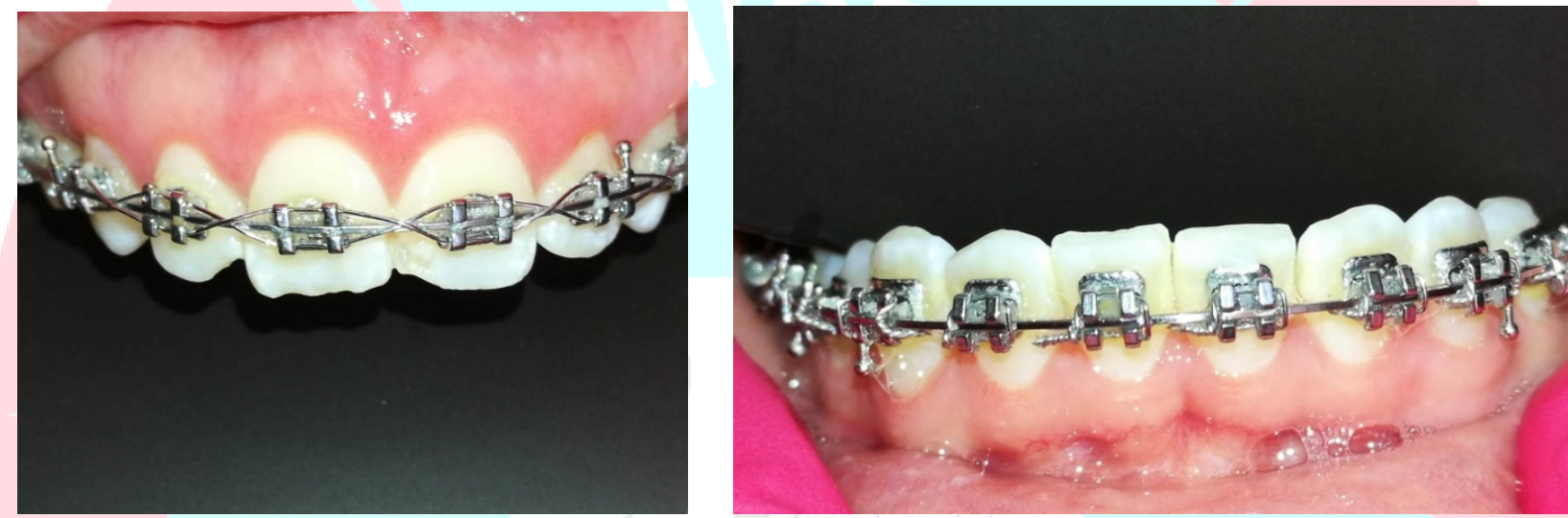

\section{fig.4 and fig.5 14 days after the manipulation}

\section{Discussion}

Because of the overgrown gingiva has an unaesthetic look, gingivectomy is necessary. There are various indications: perio aesthetic, fibrous enlargement, crown lengthening, suprabony pockets, suprabony periodontal abscesses.

Traditional gingivectomy procedures is a challenge for dentists due to its disadvantages. Nowadays, the laser procedures in the oral cavity find more use in both hard and soft tissue procedures. Laser soft-tissue surgery is well accepted by patients.(21)

The laser eliminates the need for a post-surgical dressing after traditional gingivectomy. (22) Histologically, in the biopsy taken after 7 days, less infiltration of inflammatory cells had been seen in laser with a good improved epithelization, which result in reducing the scars and the contraction of the wound and thus improve the healing (9). 
The surgery using diode laser was easier and quicker than conventional gingivectomy. The laser gingivectomy is relatively bloodless and less anesthesia is needed. Laser offers: induced coagulation, appropriate hemostasis, decreased postsurgical pain, no need for suturing, less tissue trauma, operator control and minimal collateral tissue damage.

\title{
Conclusion
}

The performed laser gingivectomy presents satisfactory aesthetic outcome, fast healing process and reduced postoperative discomfort.

\author{
Abbreviations: \\ LASER - light amplification by stimulated emission of radiation \\ CO2 - carbon dioxide \\ Nd:YAG - Neodymium: Aluminum-Yttrium-Garnet \\ Er:YAG - Erbium: Aluminum-Yttrium-Garnet \\ PVP - Polyvinylpyrrolidone
}

\section{References}

1. Agrawal AA. Gingival enlargements: Differential diagnosis and review of literature. World Journal of Clinical Cases: WJCC. 2015 Sep 16;3(9):779.

2. Bhatnagar S. Treatment of gingival enlargement, gingival disease - a professional approach for treatment and prevention, 2019, DOI: 10.5772/intechopen.82664

3. Newman MG, Takei HH, Klokkevold PR, Carranza FA, eds. (2012). Carranza's clinical periodontology (11th ed.). St. Louis, Mo.: Elsevier/Saunders. pp. 84-96.

4. Georgieva I, Targova T, Angelova S. Periodontal biotype assessment-probe transparency method-variations in relation to age and sex. Varna Medical Forum 2018, 7(1):117-123

5. Georgieva I, Peev S, Gerova T, Miteva M, Bazitova-Zlateva M. Interdental papillae height assessment in the aesthetic zone of maxilla. SSDM, 2017; 3(2): 11-16

6. Georgieva I. Tooth form assessment in the aesthetic zone of maxilla. SSDM, 2019; 5(2), 33-9

7. Georgieva I, Targova T, Angelova S, Damyanova D. Smile line-assessment and variations in relation to age and sex. Varna Medical Forum 2018, 7(1):124-130

8. Georgieva I. Prevalence of Gingival Recessions in the Aesthetic Zone of Maxilla in Bulgarian Population - IJSR, 2018 Aug; 8(7): 631-6

9. Allen E. Use of mucogingival surgical procedures to enhance esthetics. Dent Clin No Amer, 1988, 23:307-330.

10. Mosby's Dental Dictionary, 2nd edition. (c) 2008 Elsevier.

11. Garguilo, A., Wenz, F., and Orban B. Dimension and relation at the dentogingival junction in humans. Journal of periodontology; 32: 261-267 (1961).

12. Levine R. And Mcguire M. The diagnosis and treatment of the gummy smile. Compendium, 1997, 18(8): 757-764.

13. Funde S, Baburaj MD, Pimpale SK. Comparison between Laser, Electrocautery and Scalpel in the Treatment of Drug-Induced Gingival Overgrowth: A Case Report. IJSS Case Reports \& Reviews, 2015; 1(10):27-30. 
14. Mavrogiannis M, Ellis JS, Seymour RA, et al: The efficacy of three different surgical techniques in the management of drug-induced gingival overgrowth, J Clin Periodontol, 2006; 33:677-682

15. Moritz A, Schoop U, Goharkhay K, Schauer P, Doertbudak O, Wernisch J, Sperr W. "Treatment of periodontal pockets with a diode laser". Lasers in Surgery and Medicine, 1998; 22 (5): 30211.

16. Kravitz ND, Kusnoto B. Soft tissue lasers in orthodontics: An overview. American Journal of orthodontics and dentofacial orthopaedics, 2008; 4(1): 110-114.

17. The Research, Science and Therapy Committee of the American Academy of Periodontology: Lasers in Periodontics. J Periodonta, 2002l; 73:1231-9.

18. Gupta A, Jain N, Makhija PG. Clinical Applications of $980 \mathrm{~nm}$ Diode Laser for Soft Tissue Procedures in Prosthetic Restorative Dentistry. J Lasers Med Sci, 2012; 3(4):185-8

19. Ballini A, Scattarella $A$. Surgical treatment of gingival overgrowth with 10 years of follow-up. Head and Face Medicine 2010, 6:19

20. Ozcelik O, Cenk Haytac M, Kunin A, Seydaoglu G. Improved wound healing by low-level laser irradiation after gingivectomy operations: a controlled clinical pilot study. J Clin Periodontol, 2008; 35:250-4.

21. M Elakabawi. Case Reprot: Laser gingivectomy, EC Dental Science, 13.3 (2017): 112-115

22. Elavarasu S, Naveen D, Thangavelu A "Lasers in periodontics". Journal of Pharmacy \& Bioallied Sciences, 2012 Aug., 4 (2): S260-3.

\section{Corresponding author:}

Dr. Svetlana Dineva,

Periodontology and dental implantology,

Faculty of Dental Medicine Varna

email: svetlanadineva@mail.bg 